\title{
The Role of MBC in Flexible Hose in Increasing the Safety of the Process of Cutting and Prevention of Hazards in STS Condition in Triputra LNG Ship
}

\author{
Suhartini $^{1}$, B Sugiwo ${ }^{2}$, R R R S Wulandari ${ }^{3}$, D Prayogo ${ }^{4}$ \\ \{ $\underline{\text { sunisuhartini@yahoo.com }}$, bayu_sugiwo@yahoo.com ${ }^{2}, \underline{\text { shota_ku@gmail.com }}$, \\ darulprayogo@yahoo.co.id ${ }^{4}$ \} \\ ${ }^{1,2,3,4}$ STIP (Sekolah Tinggi Ilmu Pelayaran) Jakarta, Indonesia
}

\begin{abstract}
In conditions where loading and unloading activities, LNG type ships use the flexible hose in the state of ship-to-ship transfer (STS), then the safety and safety factors must be considered more. In practice, the use of flexible hose on LNG vessels is still few equipped with Emergency Release Couplings or hereinafter referred to as Marine Breakaway Couplings (MBC), because the mention of Emergency Release Couplings (ERC) is used on loading arms. Based on the existence of problems when using flexible hose in improving the security of the loading and unloading process and mitigating the danger in STS conditions on LNG-type vessels, researchers have a problem formulation that is trying to be raised in the research about the urgency of using flexible hose, namely why the use and application of Marine Breakaway couplings (MBC) in flexible hose in the process of loading and unloading LNG vessels is required. This study also has the aim to improve the safety and safety of the LNG loading and unloading process in STS conditions by using flexible hose. By using qualitative research methods, researchers found a problem solving that is to implement the use of automatic separator devices in flexible hose. By solving these problems, it is expected that when the loading and unloading process above the LNG vessel can be carried out with a good level of security.
\end{abstract}

Keywords: Flexible hose, marine break-away couplings, emergency release couplings.

\section{Introduction}

The need for transportation modes as a link between one place and another is needed[1]. The role of the transportation mode is very influential in business activities that can improve the national economy[2].

Based on the transportation function mentioned above, the researcher focuses more on sea transportation modes[3], namely in the shipping industry where commercial shipping has a major role in enhancing Indonesia's national economy. In supporting the role of the shipping industry in relation to the national economy, it is necessary to pay attention to factors that are directly or indirectly related to shipping. This supporting factor is the obligation of all parties to be maintained so that the creation of a commercial shipping industry environment is in accordance with safety and security standards[4]. 
In the commercial shipping industry, there are various kinds of cargo which are used as the main commodities of trade[5]. The researcher focused on the type of Liquefied Natural Gas (LNG) load which is the focus when researchers conduct marine work practices. LNG is the charge of natural gas which is liquefied at a temperature of about $-157 \mathrm{oC}$ at atmospheric pressure (1 atm). The LNG industry is a traded sector in the shipping sector that is developing with an increasing number of significant importing countries and is followed by an increase in the number of LNG exporting countries as providers and meeting the increasing needs of LNG The increasing number of importing countries must be followed by an increase in the amount of LNG production so that it can meet the need for LNG loads globally. This indicates that LNG is highly needed globally so that special handling is needed in ensuring safety and safety[6].

ICS OCIMF [7] LNG as alternative energy that is environmentally friendly with several advantages compared to other fossil fuels such as petroleum and coal, makes the need of LNG greatly increase so that it can overcome the needs of oil and coal globally[8].

A very significant increase in terms of demand and total production from LNG requires the availability of large amounts of LNG ship transportation modes[9]. This is evidenced by the increase in the number of LNG vessels in the last few years so that by 2017 there are 439 LNG vessels [10].

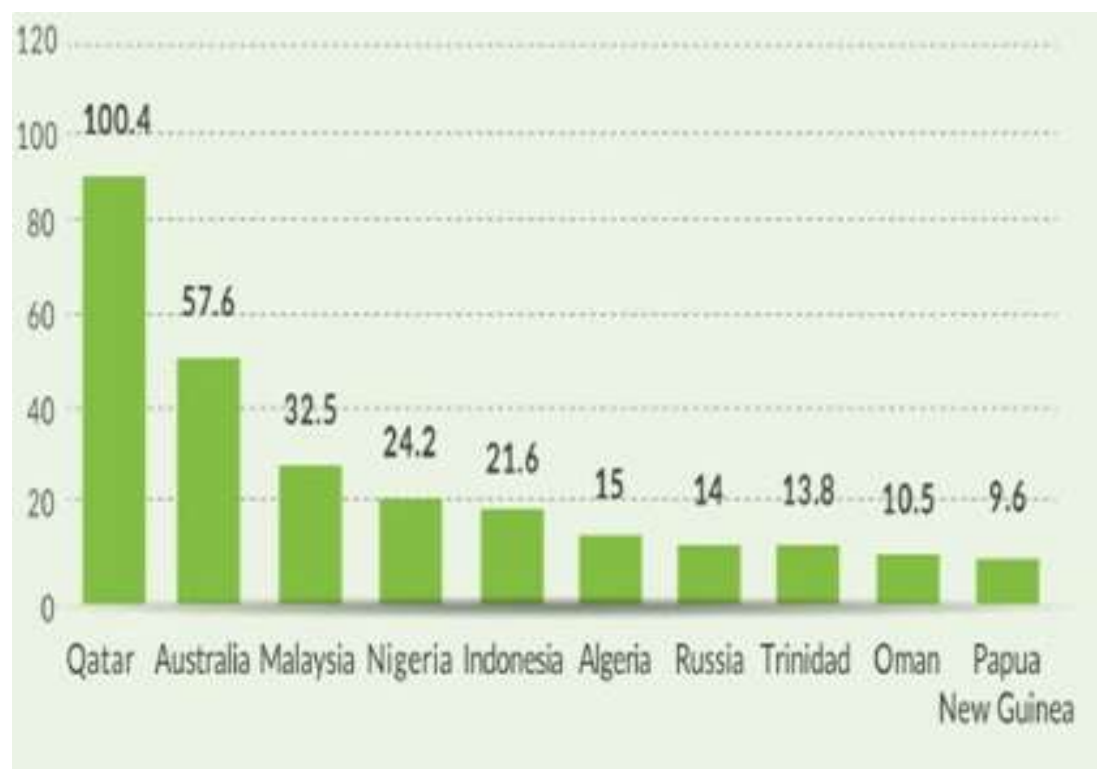

\section{Literature review}

In this chapter describes the terms and theories that are relevant in supporting the prevention and mitigation of danger situations where there are two interrelated aspects, namely; the use of MBC in flexible hose as the stage of danger prevention and safety of the shipping channel as a follow-up to the danger situation which requires the ship to leave the pier as soon as possible 


\subsection{Definitions and terms:}

\section{a. Emergency}

According to AgusHadi P, Emergency Procedure and SAR [6] Emergency Situation (Emergency Situation), is a situation outside the normal circumstances occurring on a ship that has a level of tendency will endanger the lives of humans, property and the environment in which the ship is located

\section{b. ESD (Emergency Shutdown)}

According to the SIGTTO ESD Arrangements and Linked Ship / Shore Systems for Liquefied Gas Carriers (2009: 3)

The function of the cargo emergency shutdown (ESD) system is to stop cargo liquid and vapor flow in the event of an emergency and to bring the cargo handling system to a safe, static condition.

(The function of the ESD system is to stop the flow of LNG and gas vapor in danger and keep the cargo system in a safe condition)

\section{c. ERS (Emergency Release Systems)}

ERS (Emergency Release Systems) and E According to the SIGTTO ESD Arrangements and Linked Ship / Shore System for Liquefied Gas Carriers[1].

ERS is an emergency release system, consisting of ERC mechanically linked to two isolation valves, one upstream and one downstream of the coupler. Fitted in the outboard arm of a loading arm. RC (Emergency Release Couplings)

\section{d. Break-away Couplings}

According to OCIMF, Marine Breakaway Couplings [11] paper information, Breakaway Couplings is a safety device that is applied to flexible hose which has the principle of working with ERC and will be active when the hose exceeds the maximum distance and there is a significant increase in pressure. MBC (Marine Breakaway Couplings) serves to separate and stop the flow of LNG loads in a controlled manner and prevent significant pressure increases in flexible hose. Activation of MBC will close two valves in the LNG flow so that the separation of flexible hose can be safely carried out and reduce the danger of an LNG spill.

\section{e. Marine Flexible Hose}

Marine Flexible Hose is used as a medium to move LNG cargo from the sending ship to the land or the receiving ship (under STS conditions). According to Ship to Ship Transfer Guide [5] there are no international regulations that regulate more about the use of flexible hose in STS activities and only basic guidelines are available as a reference in using flexible hose such as EN 1474-2 for LNG vessels

\section{f. Carrier LNG}

Carrier LNG Based on Liquefied Gas Handling Principles Third Edition [12] LNG vessels are grouped into 4 types based on their tank form, namely:

1) Type A Independent storage, not united with the hull structure. The shape is a prism with a flat surface, designed to carry LNG loads in a fully-refrigerated state by maintaining the pressure in the tank of 0.25-0.7 bar. Has a primary barrier and secondary barrier 
2) Type B Can have a shape with a flat surface or spherical shape (Moss type). For the Moss type storage type, it has a skirt in the tank equator so that the storage area is hanging on the skirt. Independent storage, not united with the hull structure. Has a primary barrier layer and partially secondary barrier.

\section{g. Type C}

Type C Can be spherical or cylindrical and independent. Usually to transport cargo in semi-refrigerated conditions with a pressure of 5-7 bar. Only have a primary barrier. There are several types of $\mathrm{C}$ that are fully pressurized by storing LNG loads in a maximum pressure of 18 bar.

\section{h. Membrane Type}

Membrane Type, Unlike storage types, type A, B, and C, the membrane type is not independent and is one with the hull structure. To maintain the construction of the ship from direct contact with the LNG cargo which has a very low temperature, there is a layer of intermediary (insulation space) consisting of: 1) IS (Insulation Space) 2) IBS (Inter-barrier Space) These two layers serve as a leak prevention and direct contact between LNG cargo and ship construction. At the IS and IBS layers are filled with nitrogen gas (N2) with greater pressure so as to prevent leakage and avoid gas freezing in IS and IBS.

\section{Method}

In this research writing team the research team used a qualitative descriptive approach. Descriptive approach method is a method of examining the status of a group of people, an object, a set of conditions, a system of thought, or a class of events in the present (Moh. Nazir, 2014: 43). Whereas according to Whitney (1960), descriptive method is fact-finding with the right interpretation. Descriptive research describes the symptoms that exist during the study, collects data related to the problems raised, and describes them so that they can be in the form of detailed information and provide knowledge to the reader about the issues discussed.

Qualitative research emphasizes a deep understanding of a problem that can be in the form of descriptive research and analysis of the problems raised and then developed to produce detailed information. Descriptive and qualitative approach methods complement each other and support researchers in conducting research and data collection in compiling this study

\subsection{Data Collection Techniques}

Information and data, as well as all complete information that is honest and accurate and can be accounted for, is necessary so that it can be used as basic material and become a reference in the preparation of good research. Therefore, so that the data and information can be collected, the research team uses the following data collection techniques:

\section{i. Observation technique}

That is data collection techniques carried out through direct observation on the object of research or problems that will be examined when doing a job. Data collection techniques by observation will produce primary data because it is done by observing and collecting related data directly using the eyes of the researcher without the help of other standard tools to observe something. Observation data collection techniques were carried out by researchers 
during actual work practices on SS ships. TRIPUTRA by directly observing the loading and unloading process on the use of loading arms and flexible hose along with the application of security systems in each tool. Direct observation was also carried out by researchers in the Cargo Control Room (CCR), which is a place for loading cargo on SS ships. TRIPUTRA.

\section{j. Interview Technique}

The use of data collection techniques by means of interviews in this study is about the role of safeguards during the loading and unloading process to create safe conditions and as an emergency response effort. By interviewing, researchers collected information sourced from informants about the problems in this study. The informant or resource person referred to here is the Marine Manager of HUMOLCO LNG INDONESIA, Officer of the TRIPUTRA vessel, and related parties who are considered to have valid data

\section{Result and Discussion}

SS. TRIPUTRA where researchers conduct research is an LNG vessel (LNG Carrier) which carries and transports liquefied natural gas as cargo from the loading port in Bontang, East Kalimantan to the loading port in Benoa, Bali. The transportation of LNG for the Bali region is a new and first project that began in early 2015 with the aim of generating electricity, especially in parts of South Bali. LNG loads are stored in a vessel tank in volatile conditions and the temperature is around $-157 \mathrm{oC}$ at a pressure of $2-23 \mathrm{KPa}$. The loading and unloading equipment used to move the cargo at the loading port is Loading Arm. While the port loading tool used is flexible hose.

\subsection{Use of flexible hose in the loading and unloading process that is not equipped with Marine Breakaway Couplings (MBC)}

The TRIPUTRA LNG vessel sails from the loading port in Bontang, East Kalimantan to the loading port in Benoa, Bali, carrying LNG cargo. In loading and unloading activities in Benoa using flexible hose and under STS conditions with the HAI ship YANG SHI YOU 301 which is a Chinese-flagged ship that is contracted as a storage vessel or referred to as a Floating Storage Unit (FSU) with a Goddess Granary as LNG cargo processing became gas or called the Floating Regasification Unit (FRU) behind the FSU HAI YANG SHI YOU 301

The automatic bonding safety device in the flexible hose is called Marine Breakaway Couplings (MBC). The MBC system is not directly connected to ESD, thus enabling the activation of MBC without being preceded by active ESD. However, the MBC device will be active on its own when it exceeds the maximum pressure limit that can be caused by active ESD so that there is a significant increase in pressure due to the remaining LNG load in the flexible hose and the range of flexible hose. Therefore, indirectly activating the ESD system can result in the MBC system being active in the flexible hose and supporting each other the security and safety of the loading and unloading process in an effort to prevent and mitigate danger.

In the use of flexible hose in the TRIPUTRA LNG ship loading and unloading process in Benoa, MBC has not applied the automatic bonding release device so that in a dangerous condition that cannot be overcome with ESD activation, it must be continued by manually releasing the flexible hose with the manifold. The MBC device is the development of 
industrial technology which consists of two connected impermeable valves so that in dangerous conditions it can separate and close the two valves and reduce the potential for a charge spill, avoiding the creation of a dangerous methane gas composition in the air and subsequent hazardous conditions. The application of MBC to the flexible hose has not been regulated in international regulations, but its use has fulfilled the requirements to improve safety and safety in the loading and unloading process, especially in the emergency prevention phase, which reduces the spillage of LNG loads when the flexible hose is released.

1.4 There is still a lack of knowledge on the part of the crew, especially the rating regarding prevention and handling of dangerous conditions in your loading process

At the time the TRIPUTRA LNG vessel was carrying out the process of unloading cargo in Benoa, precisely when the liquid purging process using vapor was not done optimally, the LNG load on flexible hose was used up. So that the next process is methane purging takes a long time and is not optimal. Under normal circumstances, the methane purging process is carried out using nitrogen gas which comes from the HAI YANG SHI YOU 301 vessel with a pressure that is not too high so that the process of cleaning the methane gas must be carried out around 15-18 times in approximately 1 hour to achieve optimal results namely the methane gas content $<100 \%$ of the LEL (lower explosion limit) to avoid the formation of an air condition that can burn. But at that time, the methane purging process had been carried out 18 times in more than 1 hour and the methane gas content was still 100\% from the LEL when examined using a methane detector. Then the flexible hose bond is released with dangerous conditions under the supervision of the second decker who is on the ship's manifold. These conditions are very potential for fire because the methane gas content is still more than $100 \%$ of the LEL, which means it can reach more than $5 \%$ of the volume when mixed with air and oxygen which is a sufficient composition to burn. Based on Liquefied Gas Handling Principles Third Edition (1999) methane gas cannot burn when its content of oxygen in the atmosphere is less than $5 \%$.

Based on the explanation of the cases in the previous data description, it is necessary to do data analysis as follows:

a. Use of flexible hose in the loading and unloading process that is not equipped with Marine Breakaway Couplings (MBC)

Based on field data regarding the use of flexible hose that has not been equipped with $\mathrm{MBC}$, there is no international regulation requiring the use of $\mathrm{MBC}$ in flexible hose, lack of readiness and terminal experience as a provider of flexible hose facilities that are used as loading and unloading equipment on the Benoa LNG project which is considered new and the current state of the temporary FSU HAI YANG SHI YOU 301 vessel as FSU for the Benoa LNG project, so that the supporting equipment and systems applied are still very limited and there is a need for observation, research and evaluation to improve the quality and safety and safety standards in the loading and unloading process on STS conditions by using flexible hose

b. There is still a lack of knowledge on the part of the crew, especially the rating regarding prevention and handling of hazardous conditions in the loading and unloading process.

In the event described earlier regarding flexible hose release when the methane gas content is still above the safe limit of more than $5 \%$ of the volume, it can cause methane gas to burn when mixed with oxygen and get hot sparks. 
The following will be explained about the cause rather than the problem of the lack of knowledge of the crew, especially the rating in an effort to prevent and overcome dangerous conditions, namely:

1) Familiarization that is still lacking

Familiarization is a very important thing for crewmembers more specifically for new crew members who are joining in order to introduce how to handle, maintain and operate the equipment.

2) Still lack of drill implementation

Drill or training activities are intended to habituate the crew in dealing with actual emergencies so as to improve the ability of the crew according to existing procedures. But in practice on the TRIPUTRA LNG vessel, the exercise of cargo handling in emergencies such as LNG leaks is rarely carried out

\section{Conclusion}

a. Use of flexible hose in the loading and unloading process that is not equipped with Marine Breakaway Couplings (MBC): 1). Assessment of the FSU HAI YANG SHI YOU 301 vessel as an LNG cargo storage vessel that is still temporary so that it affects the facilities used in loading and unloading activities. This was disclosed by the Marine Manager of PT. HUMOLCO LNG INDONESIA through interviews with researchers, 2).MBC equipment has not been regulated in international regulations regarding requirements than tankers carrying out loading and unloading activities using flexible hose to equip safety devices with MBC

b. There is still a lack of knowledge on the part of the crew, especially the rating regarding prevention and handling of hazardous conditions in the loading and unloading process.1) There is still a lack of familiarization carried out on crewmembers regarding handling of cargo and efforts to prevent and mitigate hazardous conditions related to LNG cargo.2) Training activities (drill) that are not carried out in accordance with the procedures specified in the document of the vessel in SMP 593-2 regarding training on LNG leakage as a precautionary and preventative phase.3) There is still a lack of preparation of documents as guidelines and regulations relating to STS activities and loading and unloading by using flexible hose such as the STS checklist that was just created and put into effect in early 2017, namely after approximately one year since the shipment of the first LNG to Benoa

\section{Suggestion}

a. Ship and Port Ownership Companies in connection with the use of flexible hose in the loading and unloading process that is not equipped with Marine Breakaway Couplings (MBC), it can be in the form of: 1). Apply the automatic separation device (MBC) to flexible hose, 2). Improving management readiness in loading and unloading activities.

b. In connection with the lack of knowledge of the crew, especially the rating regarding prevention and handling of hazardous conditions in the loading and unloading process, it can be in the form of: 1). Implementation of familiarization to new crew, 2) Implementation of training (drill) according to procedures, 3). Improved management system 
c. Port Authority, Based on the problem of the heavy flow of the shipping bay of Benoa Bay that endangers ship traffic, it can be in the form of advice, namely:1) Increase the number of boat patrols and escort vessels, 2) Limitation of the number of ships in the port, 3) Making regulations to separate between LNG port and passenger/tourist port, d). Dissemination to the public about the importance of maintaining security and equipment of the shipping channel

\section{References}

[1] ABS, ABS Gas Carrier Course. Cheshire: ABS, 2003.

[2] British Petroleum, "Statistical Review LNG of World Energy 2017," 2017.

[3] British Standard, EN 1473 Installation and Equipment for Liquefied Gas - Design of onshore installations. London: British Standard, 1997.

[4] British Standard, EN 1474 Installation and Equipment for Liquefied Gas - Design and Testing of laoding/unloading arms. London: British Standard, 1997.

[5] Oil Companies International Marine Forum, Ship to Ship Transfer Guide for Petroleum, Chemical and Liquefied Gases. Scotland: Witherby Seamanship International Ltd, 2013.

[6] A. Nascetti et al., "Fast terrain modelling for hydrogeological risk mapping and emergency management: the contribution of high-resolution satellite SAR imagery," Geomatics, Nat. Hazards Risk, vol. 6, no. 5-7, pp. 554-582, 2015.

[7] International Chamber of Shipping \& Oil Companies International Marine Forum, The International Safety Guide for Oil Tankers and Terminals. London: Witherby\& Co Ltd, 2006.

[8] \& O. C. I. M. F. International Chamber of Shipping, A Contingency Planning and Crew Response Guide for Gas Carrier Damage at Sea and in Port Approaches Third Edition. London: Witherby\& Co Ltd, 1999.

[9] \& O. C. I. M. F. International Chamber of Shipping, A Guide to Contingency Planning for The Gas Carrier Alongside and Within Port Limits Second Edition. London: Witherby\& Co Ltd, 1999.

[10] International Gas Union, “2017 World LNG Report,” Barcelona, 2017.

[11] Oil Companies International Marine Forum, "Marine Breakaway Couplings Information Paper," Oil Companies International Marine Forum. 2008.

[12] G. McGuire and B. White, Liquefied Gas Handling Principles On Ships and in Terminals Third Edition. London: Witherby \& Co Ltd, 1999. 